\title{
Patients with adenomatous polyps and carcinomas have increased colonic mucosal prostaglandin $\mathrm{E}_{2}$
}

\author{
S Pugh, G A O Thomas
}

\begin{abstract}
Colorectal carcinoma in humans and animal models is associated with increased synthesis of prostaglandin $\mathrm{E}_{2}\left(\mathrm{PGE}_{2}\right)$. $\mathrm{PGE}_{2}$ synthesis was measured in normal and neoplastic human colorectal mucosa to investigate its role in the adenoma-carcinoma sequence. Paired mucosal biopsy specimens for $\mathrm{PGE}_{2}$ synthesis and histological examination were obtained during 39 diagnostic colonoscopies. Twelve control patients in whom colonoscopies and histology were normal synthesised similar amounts of $\mathrm{PGE}_{2}$ at all sites. Their results were (mean (SD) pg PGE $2 / \mathrm{mg}$ tissue) caecum $102.8(15.9)(n=6)$, ascending colon 110.8 $(24 \cdot 3)(n=10)$, transverse colon $103.9(19.5)$ $(n=11)$, descending colon $102.9(23 \cdot 2)(n=12)$, sigmoid colon $96.4(18.0)(n=12)$, and rectum $107 \cdot 1(17 \cdot 6)(n=12)$. Nineteen patients had a total of 27 adenomatous polyps (rectum (1), sigmoid (22), descending (1), transverse (1), and ascending colon (1): histology - tubular (16), tubulo-villous (8), and villous adenomous (3)). The polyps $(178.0(55.0), \mathbf{n}=27)$ synthesised more $\mathrm{PGE}_{2}$ than controls $(\mathbf{p}<\mathbf{0 . 0 0 1})$, but the values in polyp-associated mucosa (mean (SD) $115.4(21.9), n=15)$ were not different to control results. Eight patients had carcinomas (rectal (2), sigmoid (4), and caecal (2)) all of which were adenocarcinomas. The cancers $(193.6(40 \cdot 2), n=8)$ synthesised more $\mathrm{PGE}_{2}$ than control specimens $(\mathrm{p}<\mathbf{0 . 0 0 1})$, but were not different to polyps. Cancerassociated mucosa $(140.3(27.7) \quad n=8)$ synthesised more PGE $_{2}$ than control and polypassociated mucosa. Colorectal neoplasia is associated with a progressive increase in $\mathrm{PGE}_{2}$ synthesis which may have a role in tumourigenesis and be a pathophysiological explanation for the beneficial effects of NSAIDs in animal models and human disease.

(Gut 1994; 35: 675-678)
\end{abstract}

Department of Surgery, Rayne Institute, University College London, University Street, London $S$ Pugh

Department of Gastroenterology, University Hospital of Wales, Heath Park, Cardiff

G A O Thomas

Correspondence to: Dr S Pugh, Department of Gastroenterology, Llandough Hospital NHS Trust, Penarth, Cardiff.

Accepted for publication 13 August 1993
Human and animal work in colorectal carcinogenesis has suggested an association with increased prostaglandin (PG) synthesis. Transformation from premalignant to a malignant state may be related to increased PG synthesis in susceptible individuals. Prostanoids, in particular $\mathrm{PGE}_{2}$ are produced in increased amounts by human colonic tumour cells. ${ }^{2}$ Prostaglandins may play a role in tumour development and progression; they modulate tumour cell growth and facilitate tumour cell progression. ${ }^{3+}$

Animal models of colorectal cancer have shown increased prostaglandin production from carcinoma cells. ${ }^{5}$ In addition, it has been shown that non-cancerous or background mucosa in tumour bearing animals produces increased amounts of $\mathrm{PGE}_{2}$. It has been suggested that the development of large bowel tumours may be related to the level of prostaglandin synthesis. ${ }^{6}$ The ability of certain NSAIDs to suppress colonic tumourigenesis in animal models of colorectal cancer implies that PGs are involved..$^{7-9}$

We have, therefore, investigated the changes in colonic mucosal $\mathrm{PGE}_{2}$ synthesis in the human adenoma-carcinoma sequence.

\section{Methods}

\section{COLONOSCOPIC EXAMINATION}

Thirty nine patients had a diagnostic colonoscopy performed by a single colonoscopist (SP). In each case, after giving informed consent, the patient was placed in the left lateral position and sedated by intravenous injection of individually titrated doses of diazepam (5-20 mg) and pethidine (0-100 mg) according to the patient's age, weight, and clinical response. Patients underwent digital per-rectal examination and wherever possible a full diagnostic colonoscopy was performed using a standard flexible fibre optic colonoscope (Olympus).

\section{Controls}

Patients with normal colonoscopies had paired biopsy specimens taken from the caecum and ascending, transverse, descending, and sigmoid colons and rectum.

\section{Colorectal neoplasia}

Patients with polyps, or a carcinoma, had paired background biopsy specimens taken from normal looking mucosa at least $10 \mathrm{~cm}$ away from the lesion. The polyp or cancer was then biopsied. Polyps were removed by snare diathermy and retained for histological examination. In the case of suspected carcinoma multiple biopsy speciments were taken for histological examiantion.

\section{HISTOLOGICAL EXAMINATION}

Tissue specimens were placed in formalin and histological examination was undertaken by the Department of Histology, University College Hospital, London. Reports were issued by a consultant histopathologist.

PROSTAGLANDIN SYNTHESIS

Biopsy tissues for $\mathrm{PGE}_{2}$ synthesis were transferred immediately in ice cold Tris buffer ( $\mathrm{pH}$ 8.4 ) and processed within one hour. The method 
of prostaglandin generation and validation is given elsewhere. ${ }^{10}$ Briefly, the sample was washed with Tris buffer, blotted dry on Whatman's no 1 filter paper, and weighed using an electronic balance (Metler AC100). The specimen was then resuspended in $1 \mathrm{ml}$ of Tris buffer and ultracentrifuged for exactly 15 seconds in a fixed speed Hawksley microhaematocrit centrifuge (giving $10000 \mathrm{rpm}$ ). The supernatant was discarded and replaced with $0.05 \mathrm{ml}$ Tris buffer and the biopsy was vortexed for exactly 60 seconds using a bench vortex mixer. The formation of PDs was stopped by the addition of $0.01 \mathrm{ml}$ of indomethacin in ethanol (to give a final concentration of $10 \mu \mathrm{g} / \mathrm{ml}$ ) and the total volume made up to $1 \mathrm{ml}$ by the addition of $0.94 \mathrm{ml}$ of Tris buffer.

\section{MUCOSAL PGE ${ }_{2}$ IN COLORECTAL POLYPS AND \\ CANCER}

The biopsy tissue and additions were then recentrifuged as above and the supernatant divided into two aliquots and stored at $-20^{\circ} \mathrm{C}$. Aliquots were batch assayed by highly specific radioimmunoassay (anti-PGE ${ }_{2}$ antibody, Sigma) for $\mathrm{PGE}_{2}$ in duplicate and two dilutions, and with reagent and sample blanks. The final results are expressed as pg $\mathrm{PGE}_{2} / \mathrm{mg}$ weight of tissue.

\section{STATISTICAL ANALYSIS}

The PG synthesis results were compared by Student's $t$ test for unpaired data. Significance was defined at $p<0.05$ level. Correlations were analysed by regression analysis.

\section{ETHICAL APPROVAL}

Ethical approval was obtained from the Ethics Committee, University College London, and

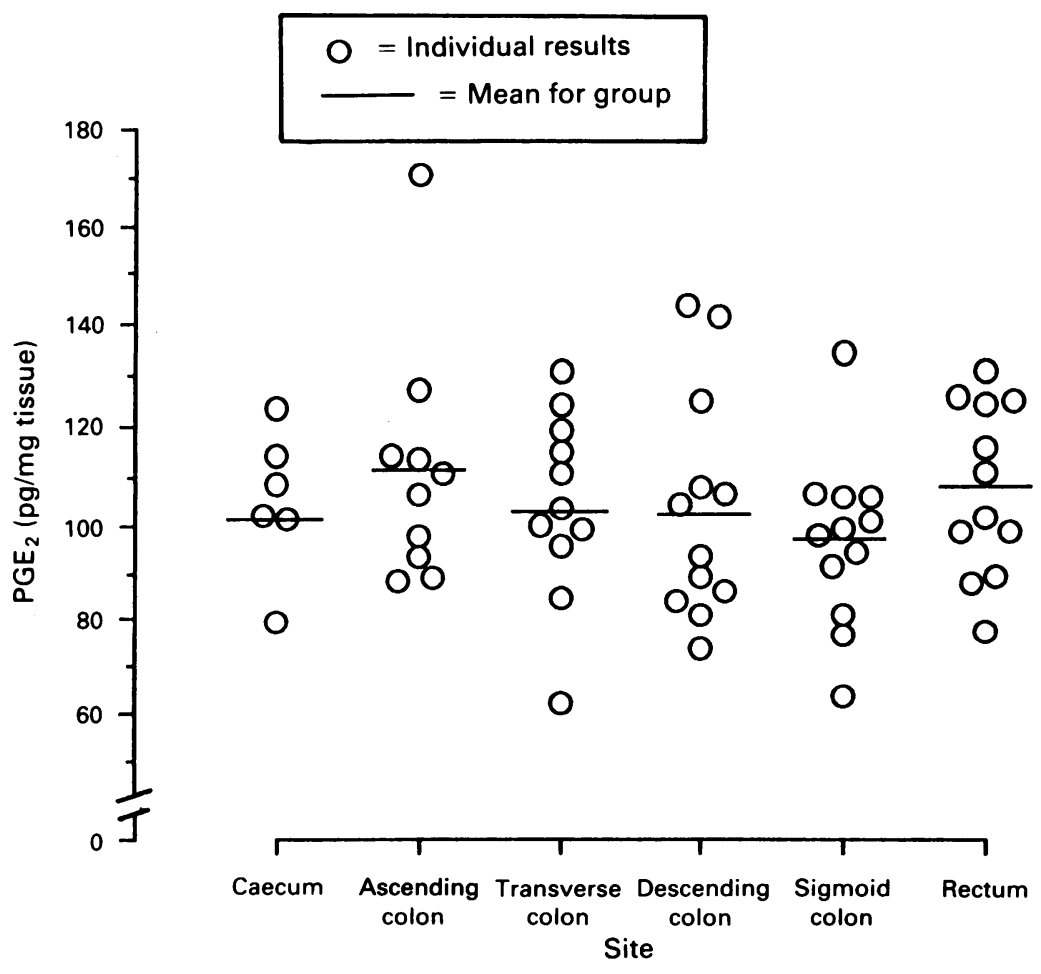

Figure 1: Prostaglandin $E_{2}\left(P G E_{2}\right)$ synthesis throughout the colon in control subjects. written informed consent was obtained from each patient.

\section{Results}

\section{COLONOSCOPIC AND HISTOLOGICAL FINDINGS}

\section{Controls}

Twelve patients (seven men, five women; mean (SD) age 60.1 (15.4) years) had normal colonoscopic and histological examinations.

\section{Polyps}

Nineteen patients (nine men, 10 women; mean (SD) age $65.0(12.3)$ years) had a total of 27 adenomatous polyps removed at colonoscopic examination.

\section{Carcinomas}

Eight patients (four men, four women; mean (SD) age $74.5(16.7)$ years) had histologically proved colorectal carcinomas.

\section{Age}

There was no difference in sex ratios between the three clinical groups. Control patients and patients with polyps were similar in age. However, patients with colorectal cancer were older than the control group $(p<0.02)$ but not older than patients with polyps.

\section{Site and histology}

As expected, most of the polyps were found in the distal colon. One was found in the rectum, 22 in the sigmoid, two in the descending, and one each in the transverse and ascending colons. There were two rectal carcinomas, four sigmoid carcinomas and two caecal carcinomas. Most polyps were tubular adenomas (16), eight were tubulo-villous adenomas, and three villous adenomas. The carcinomas were all adenocarcinomas.

\section{PROSTAGLANDIN SYNTHESIS}

\section{Controls}

Results of $\mathrm{PGE}_{2}$ synthesis for different areas of the colon were (values mean (SD) $\mathrm{pg} \mathrm{PGE}_{2} / \mathrm{mg}$ tissue) caecum $102 \cdot 8(15 \cdot 9)(n=6)$; ascending $110.8(24.3)(n=10)$, transverse $103.9(19.5)$ $(n=11)$, descending $102.9(23 \cdot 2)(n=12)$, and sigmoid colons $96.4(18.0)(n=12)$; and rectum $107 \cdot 1(17 \cdot 6)(n=12)$. The distribution of the individual results are shown in Figure 1. There were no differences between areas in the ability to synthesise $\mathrm{PGE}_{2}$, nor was there any trend in synthesis ability from right to left within the colon.

\section{Patients with colorectal neoplasia}

Biopsy specimens from the background mucosa of patients with polyps synthesised (mean (SD)) $115.4(21.9)(\mathrm{n}=15) \mathrm{pg} \mathrm{PGE}_{2} / \mathrm{mg}$ tissue. Where- 


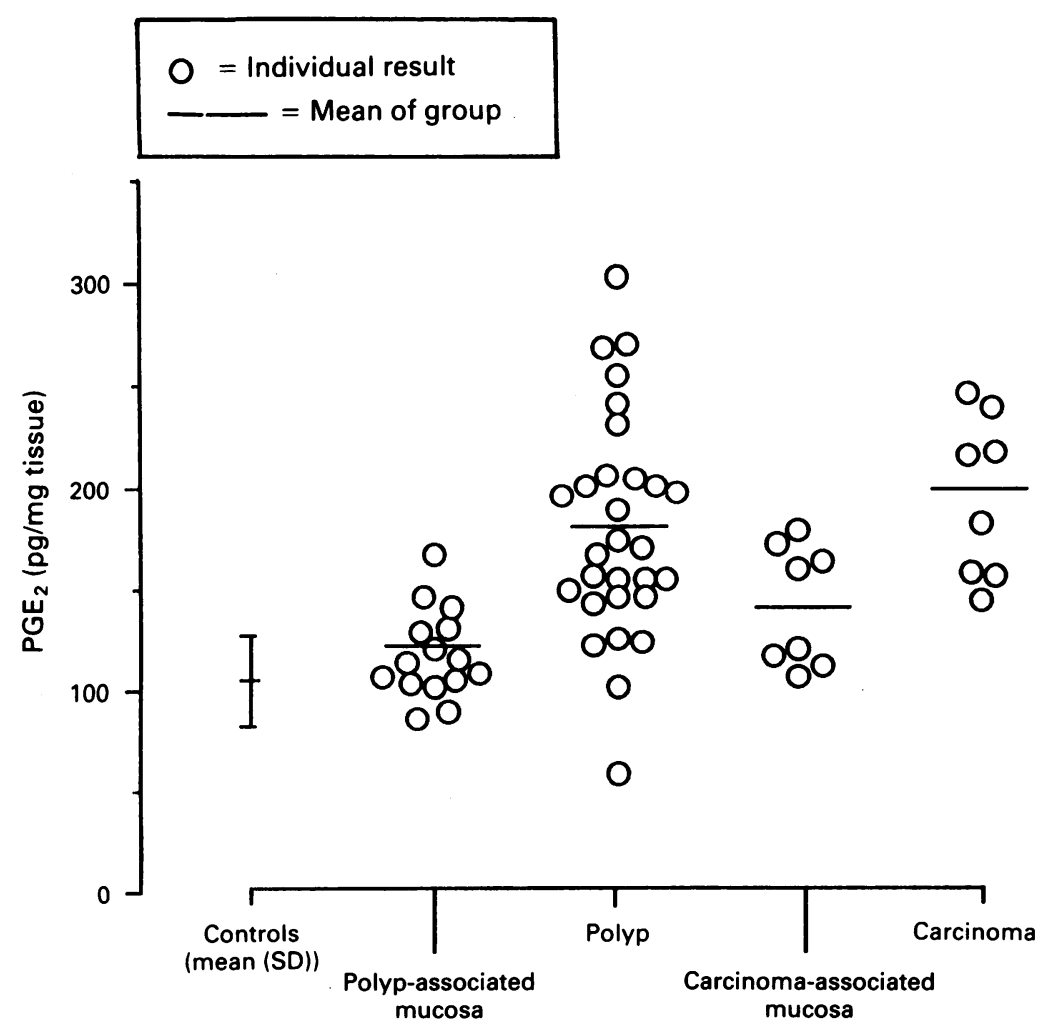

Figure 2: Prostaglandin $E_{2}\left(P G E_{2}\right)$ synthesis in polyps, carcinomas, and their associated mucosa. known that PGs are involved in proliferation and metastasis. "It is also known that $\mathrm{PGE}_{2}$ has an effect on the immune system, and may reduce immunosurveillance and promote tumour development. ${ }^{13}$

One of us, with others, ${ }^{1+}$ has shown a persistent increase of $\mathrm{PGE}_{2}$ synthesis in the colonic mucosa of rats after treatment with the colonic carcinogen 1,2 Dimethylhydrazine (DMH) - a change which was found in background mucosa and in resulting polyps and cancers. Although the increase in $\mathrm{PGE}_{2}$ could be a secondary response to the carcinogen, the persistence of the increase long after the initial exposure suggests that it is not. Likewise, the presence of increased PG synthesis before detection of cancers suggests that such an increase is not a product of the tumour cell mass. Similarly, N'-methyl-N'-nitro-N-nitroguanidine (MNNG) induced colonic carcinoma has been found to be associated with high levels of $\mathrm{PGE}_{2}$ synthesis at all stages of tumour formation compared with controls, and again significantly increased synthesis was shown before tumour development. ${ }^{6}$

The suggestion that increased $\mathrm{PGE}_{2}$ synthesis may be important in colonic tumourigenesis has important therapeutic implications. Animal models have shown that certain non-steroidal anti-inflammatory drugs (NSAIDs) can reduce the number of tumours included by various carcinogens. $^{7-9} 1516$ Among those actions of NSAIDs which may be anti-carcinogenic is their ability to inhibit PG synthesis. Indomethacin has been shown to enhance lymphocyte function and responses to mitogens in patients with colonic cancer. ${ }^{14}$ partly through suppression of monocyte $\mathrm{PGE}_{2}$ synthesis. Indomethacin also has an effect on the cellular immune system that is not dependent on PGs. ${ }^{17}$

The association of reduced PG synthesis, NSAIDs, and the suppression of tumourigenesis in animal models has prompted studies into the potentially beneficial effect of NSAIDs in human colorectal neoplasia. Initial anecdotal reports that sulindac (Clinoral, MSD) caused regression of polyps in patients with familial polyposis and Gardener's syndrome ${ }^{18}$ have been confirmed in a controlled trial. ${ }^{19}$ The incidence of colorectal cancer is also reduced in regular users of aspirin. $^{2021}$

There has been recent interest in the role of diet in colorectal cancinogenesis. There is evidence that the consumption of fish products rich in w-3 fatty acids may protect against colorectal cancer, perhaps through their ability to inhibit cyclo-oxyganase and reduce $P G$ synthesis. 22

Our findings that $\mathrm{PGE}_{2}$ synthesis is increased in premalignant adenomatous polyps and in the background mucosa of those patients with colorectal cancer, suggests that $\mathrm{PGE}_{2}$ may be involved in the progression of the adenomacarcinoma sequence. We postulate that mucosal $\mathrm{PGE}_{2}$ is increased in susceptible individuals in response to an unknown stimulus and that this promotes tumorigenesis. If this is the case, the use of NSAIDs and dietary changes to prevent the recurrence of colonic polyps and colorectal cancer deserves wider study in at risk groups. 
1 Jaffe BM, Parker CW, Philpott GW. Immunochemical measurement of prostaglandin or prostaglandin-like activity from normal an neoplastic cultured tissue. Surgical Forum 1971; 22: 90-2.

2 Bennett A, Del Tacca M, Stamford IF, Zebro T. Prostaglandins from tumours of human large bowel. $\mathrm{Br} \mathcal{F}$ Cancer 1977; 35: 881-4.

3 Honn KV, Bockmann RS, Marnett LJ. Prostaglandins and cancer: a review of tumour initiation through tumour cancer: a review of tumour initiation thro
metastasis. Prostaglandins 1981; 21: 833-64.

4 Jaffe BM. Prostaglandins and cancer: an update. Prostaglandins 1974; 6: 453-61

5 Tanka $M$, Nazkazawa $S$, Koike $M$. Investigation of endogenous prostaglandins in DMH-induced colonic cancer in rats. $\mathcal{F}$ Gastroenterol 1985; 82: 592-8.

6 Yamaguchi A, Ishida T, Nishimura G, Katoh M, Miyazaki I Investigation of colonic prostaglandins in carcinogenesis in the rat colon. Dis Colon Rectum 1991; 34: 572-6.

7 Metzger U, Meier J, Uhlschmid G, Weihe H. Influence of various prostaglandin synthesis inhibitors on $\mathrm{DMH}$-induced rat colon cancer. Dis Colon Rectum 1984; 27: 366-9.

8 Reddy BS, Maruyama H, Kelloff G. Dose-related inhibition of colon carcinogenesis by dietary piroxicam, a non-steroidal anti-inflammatory drug, during different stages of rat colon tumour development. Cancer Res 1987; 47: 5340-7.

9 Craven PA, DeRubertis FR. Effects of aspirin on 1,2-dimethylhydrazine-induced colonic carcinogenesis. 1,2-dimethylhydrazine-induce

10 Pugh S, Williams SE, Lewin MR, Ishaque M, Barton TP, Bose $\mathrm{K}$, et al. Duodenal and antral mucosal prostaglandin $\mathrm{E}_{2}$ synthesis in a study of duodenal ulcer disease treated by $\mathrm{H}_{2}$ receptor antagonists. Gut 1989; 30: 161-5.

11 Narisawa T, Kusaka H, Yamazaki Y, Takahashi M, Koyama $\mathrm{H}$, Koyama $\mathrm{K}$ et al. Relationship between blood plasm prostaglandin $\mathrm{E}_{2}$ and liver lung metastases in colorectal cancer. Dis Colon Rectum 1990; 33: 840-5.
12 Karmali K. Prostaglandins and cancer. CA 1983; 33

13 Balch CM, Dougherty PA, Cloud GA, Tilden AB. Prostaglandin $\mathrm{E}_{2}$-mediated suppression of cellular immunity in colon cancer patients. Surgery 1984; 95: 71-7.

14 Pugh S, Gellister JSK, Williams SE, Lewin MR, Barton TP Clark CG, et al. Prostaglandin $\mathrm{E}_{2}$ changes precede tumour Cormation in the dimethylhydrazine colon cancer model in rats. Dig Dis Sci 1986; 31 (10): $363(\mathrm{~S})$.

15 Narisawa T, Satoh M, Sano M, Takahashi T. Inhibition of initiation and promotion by $\mathrm{N}$-methylnitrosurea-induced colon carcinogenesis in rats by the NSAID indomethacin. colon carcinogenesis in rats by

16 Pollard M, Luckert P. Prevention and treatment of primary intestinal tumours in rats by piroxicam. Cancer Res $1989 ; 49$ : $6741-73$

17 Tilden AB, Balch CM. Immune modulatory effects of indomethacin in melanoma patients are not related to prostaglandin $E_{2}$-mediated suppression. Surgery 1982; 92: $528-32$

18 Waddell WR, Longhry RW. Sulindac for polyposis of the colon. F Surg Oncol 1983; 24: 83-7.

19 Labayle D, Fischer D, Vielh P, Drouhin F, Pariente A, Bories $\mathrm{C}$, et al. Sulindac causes regression of rectal polyps in familial polyposis coli. F Gastroenterol 1991; 101: 635-9.

20 Thun MJ, Namboodiri MM, Clark WH Jr. Aspirin use and reduced risk of fatal colon cancer. New Engl F Med 1991; reduced risk

21 Kune GA, Kune S, Watson LE. Colorectal cancer risk chronic illnesses, operations, and medications: Case control results from the Melbourne colorectal cancer study. Cancer Res 1988; 48: 4399-404.

22 Anti M, Marra G, Armelao F, Bartoli GM, Ficarella R, Percesepe A, et al. Effect of w-3 fatty acids on rectal mucosa cell proliferation in subjects at risk for colon cancer. Gastroenterology 1992; 103: 883-91. 